\title{
A Systematic Review of the Respiratory Effects of Inhalational Marijuana
}

\author{
Mary P Martinasek PhD MPH RRT, Jamie B McGrogan, and Alisha Maysonet
}

\author{
Introduction \\ Review of the Literature \\ Search Strategies \\ Results \\ Conclusions
}

\begin{abstract}
This systematic review focuses on respiratory effects of inhalational marijuana. The systematic review of the literature was conducted using a comparative method between 2 researchers. Abstracts were reviewed for inclusion of respiratory effects related to inhalational marijuana. Relevant abstracts were collected, and full text articles were retrieved for review. Articles were removed if they did not contain burning marijuana; were animal studies; or were editorials, systematic reviews, commentaries, non-English language, or non-respiratory-related articles. Forty-eight articles were collected and categorized by respiratory effects. In particular, lung cancer, bullous emphysema/COPD, and other respiratory symptoms were the primary categories. Articles were noted by study population country, sample size, age distribution, and findings that were pertinent to respiratory health. The research indicates that there is a risk of lung cancer from inhalational marijuana as well as an association between inhalational marijuana and spontaneous pneumothorax, bullous emphysema, or COPD. A variety of symptoms have been reported by inhalational marijuana smokers, including wheezing, shortness of breath, altered pulmonary function tests, cough, phlegm production, bronchodilation, and other symptoms. It is important to stay current with research findings to educate patients on this smoking behavior. Key words: cannabis; marijuana; inhalational; respiratory; symptoms. [Respir Care 2016;61(11):1543-1551. @ 2016 Daedalus Enterprises]
\end{abstract}

\section{Introduction}

Cannabis (marijuana) is the most commonly used drug in the United States and abroad. Marijuana consists of the dried leaves and flowers of the Cannabis sativa plant.

The authors are affiliated with the University of Tampa, Department of Health Sciences and Human Performance, Tampa, Florida.

The authors have disclosed no conflicts of interest.

Correspondence: Mary P Martinasek PhD, MPH, RRT, $401 \mathrm{~W}$. Kennedy Boulevard, Box 30F, University of Tampa, Tampa, FL 33618. E-mail: MMartinasek@ut.edu.

DOI: $10.4187 /$ respcare. 04846
Because of environmental influences on plant growth, chemical potency varies. ${ }^{1}$ Over 60 cannabinoids and 400 compounds have been identified in marijuana. ${ }^{2}$ Most common among these cannabinoids is THC $(1-\delta$-9-tetrahydrocannabinol), which is believed to be the primary cannabinoid responsible for the psychoactive effects produced from consumption. The primary differences between marijuana smoke and cigarette smoke are the cannabinoids in marijuana and the nicotine in cigarette smoke. Nicotine is known to be the addictive substance of cigarette smoking. With the illicit nature of marijuana, less research has been conducted on the constituents of the smoke and on the respiratory effects of inhalational marijuana. However, both contain cancer-causing nitrosamines, polycyclic aromatic hydrocarbons, vinyl chlorides, and phenol. ${ }^{3}$ 
Table 1. Search Terms and Databases

\begin{tabular}{ll}
\hline \multicolumn{1}{c}{ Databases } & \multicolumn{1}{c}{ Terms } \\
\hline PubMed & Advanced term "Marijuana" \\
OVID & Marijuana smoking and respiratory system \\
& Cannabis: adverse effects \\
& Marijuana smoking: epidemiology \\
Web of Science & Marijuana smoking/epidemiology \\
& Cannabis/adverse effects* \\
& Marijuana smoking/epidemiology* \\
& Marijuana smoking/physiopathology \\
& Lung diseases/chemically induced \\
& Marijuana smoking/adverse effects* \\
& Respiratory system/drug effects* \\
& Marijuana abuse/respiratory complications \\
\hline
\end{tabular}

Before the Marijuana Tax Act of 1937, cannabis was used medicinally, and in 1970, it was classified as a Schedule 1 drug due to the potential for abuse, lack of acceptance as medical treatment, and lack of safety. ${ }^{4}$ Other drugs in the Schedule 1 category include heroin, ecstasy, and lysergic acid diethylamide (LSD). ${ }^{5}$ Over the past several years, legalization of recreational cannabis has occurred in 4 states and the District of Columbia, which will help to propel and allow more research on this formerly illicit drug. ${ }^{6}$ The use of cannabis has steadily increased over the years, with current past month users estimated at 19.8 million people. ${ }^{7}$ Adolescent use and perception has remained stable in recent years according to the National Institutes of Health. ${ }^{8}$ Nearly $64 \%$ of high school seniors in 2014 viewed cannabis as being not harmful compared with $35 \%$ in 1994.

The widespread use of marijuana has raised concerns for medical practitioners regarding the long-term respiratory effects. Most research has considered mental health effects, but research on respiratory effects has not been explored recently. Our systematic review of the literature serves to describe what empirical literature exists on the respiratory effects of inhalational cannabis, in particular. Although cannabis is consumed in various forms, our research study and comprehensive literature review was particularly focused on the inhalational effects to better serve as a comprehensive guide for respiratory therapists, pulmonologists, and others in the health-care field.

\section{Review of the Literature}

\section{Search Strategies}

Inhalational marijuana peer-reviewed articles published from 1967 to 2015 were identified from the PubMed, OVID, and Web of Science databases using the search terms shown in Table 1. Retrieval of the peer-reviewed articles was

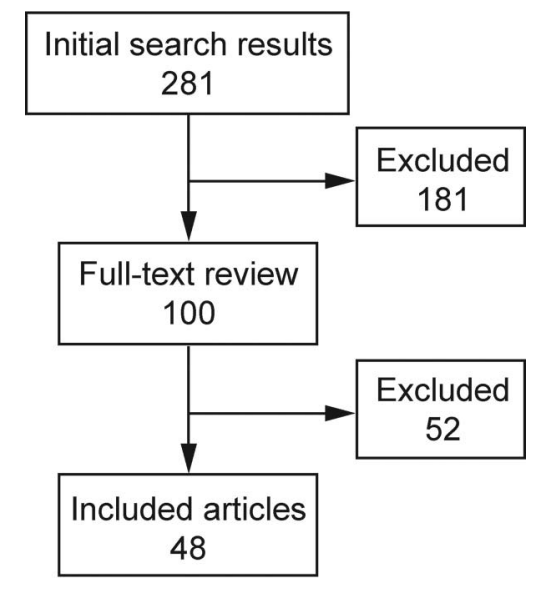

Fig. 1. Flow chart.

performed by 2 researchers (JBM and AM). The initial review commenced with an abstract review to exclude any commentary letters, reviews, editorials, non-English language studies, and animal studies (ie, non-research studies applicable to respiratory, synthetic marijuana, and medical cannabis). Additionally, the reviewers restricted the search to inhalational marijuana only and were focused only on its respiratory health effects.

The search term "lung diseases/chemically induced" revealed 27,220 abstracts. An advanced search on "lung diseases/chemically induced" was conducted using the term "marijuana" and resulted in one abstract therefore, similar search with term "respiratory system/drug effects*" yielded 2,548 abstracts. Abstracts that could not be categorized based on the lack of information provided in the abstract were reviewed in full text form to allow a final decision regarding classification.

We identified 281 abstracts (250 from PubMed, 2 from OVID, and 29 from Web of Science) through the literature search, as noted in Figure 1. Omitted abstracts included any duplicates, systematic reviews, editorials, commentaries, non-English language articles, animal studies, unattainable full text articles, or those that were not inclusive of respiratory health. An additional 19 unidentified abstracts were listed but provided no direct access to the full text. Of these, 100 articles were reviewed for inclusion. Fifty-two were removed for lack of fit with the inclusion criteria. The final 48 articles were included in this systematic review.

After review of the articles, we developed a matrix to delineate articles by date of publication, study design, study population and country, age of study participants, and findings deemed important to respiratory health. Furthermore, the studies were organized into tables by disease. Table 2 indicates studies that primarily addressed lung cancer; Table 3 describes studies related to bullous emphysema, COPD, or pneumothorax; and Table 4 categorizes studies 


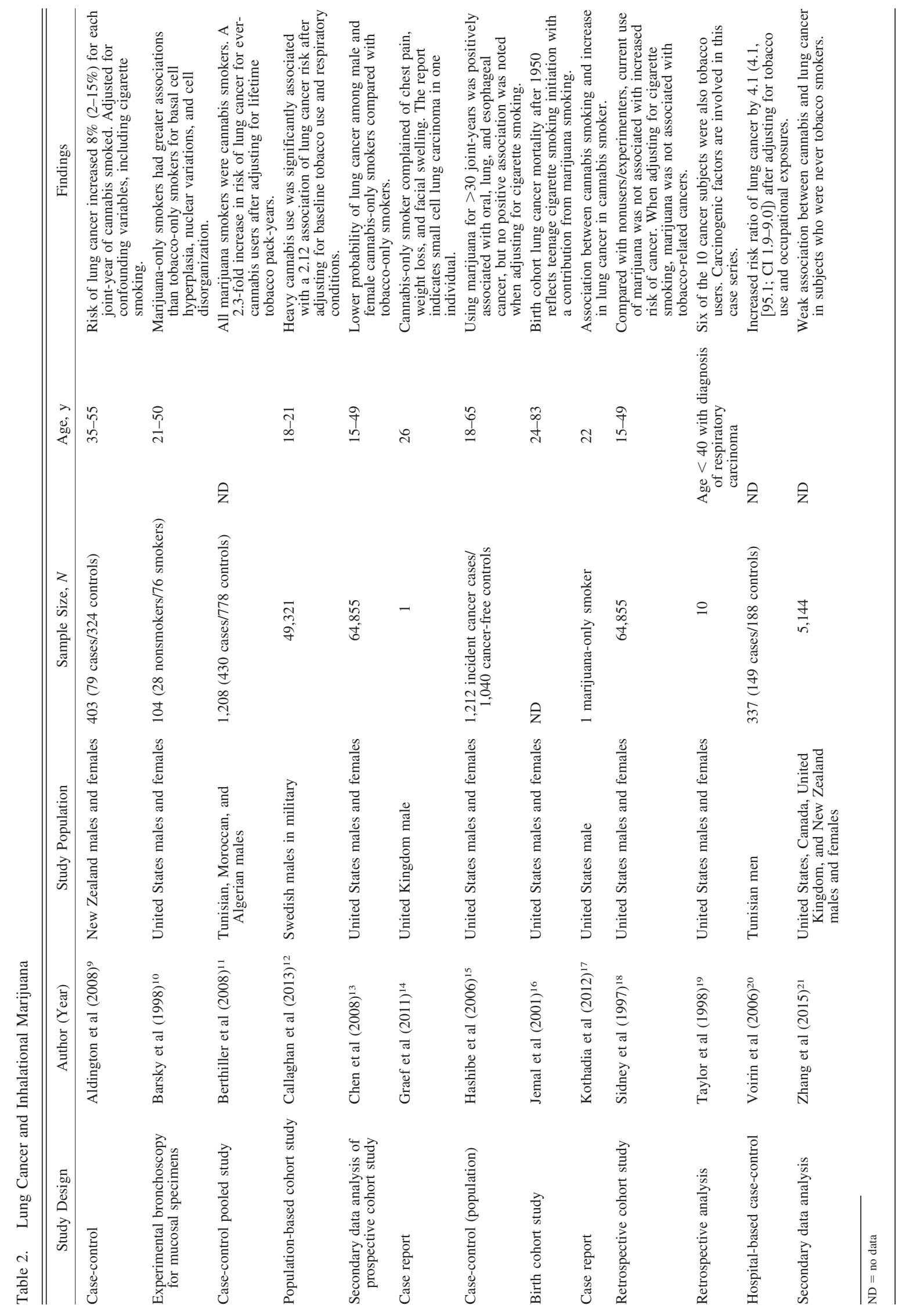




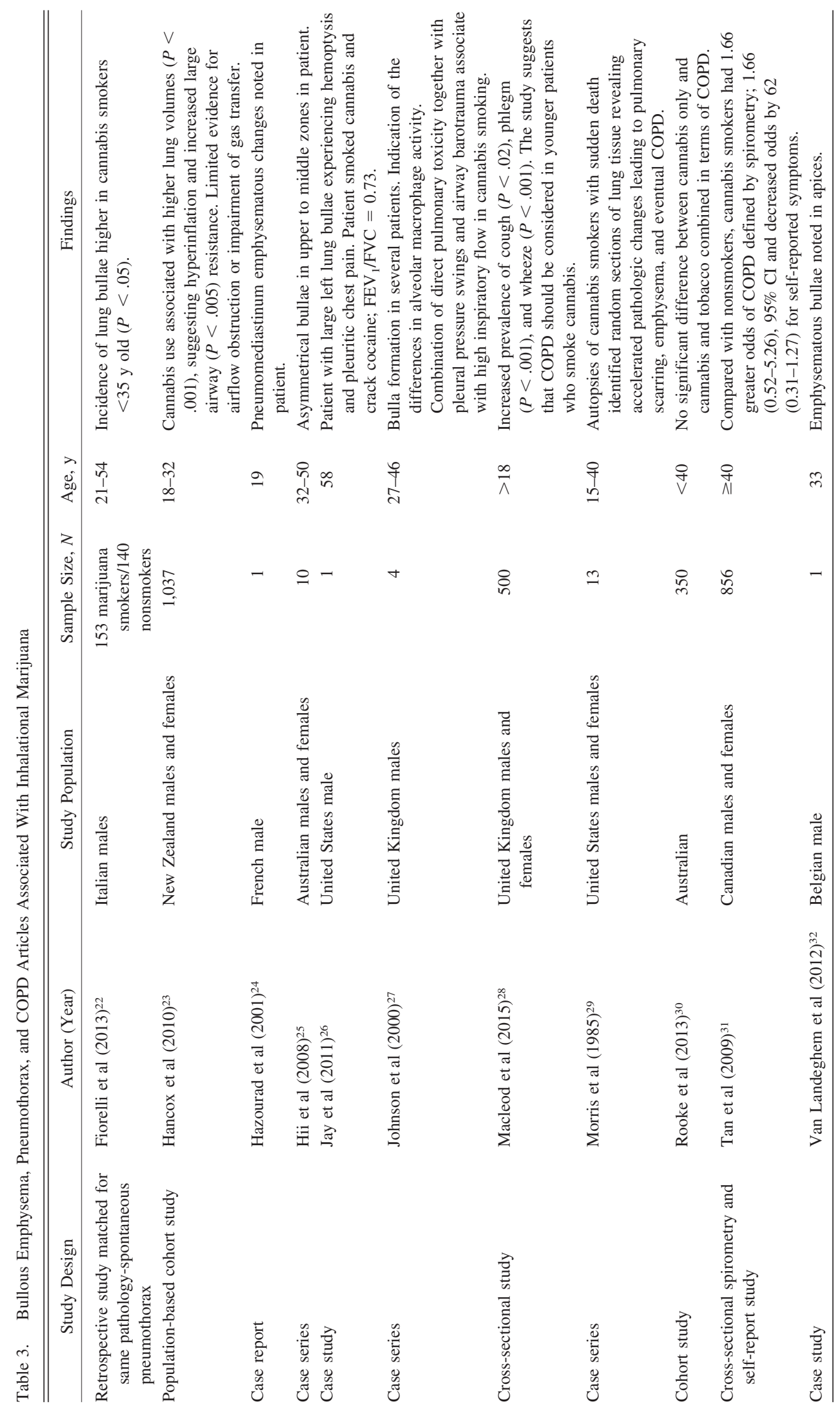




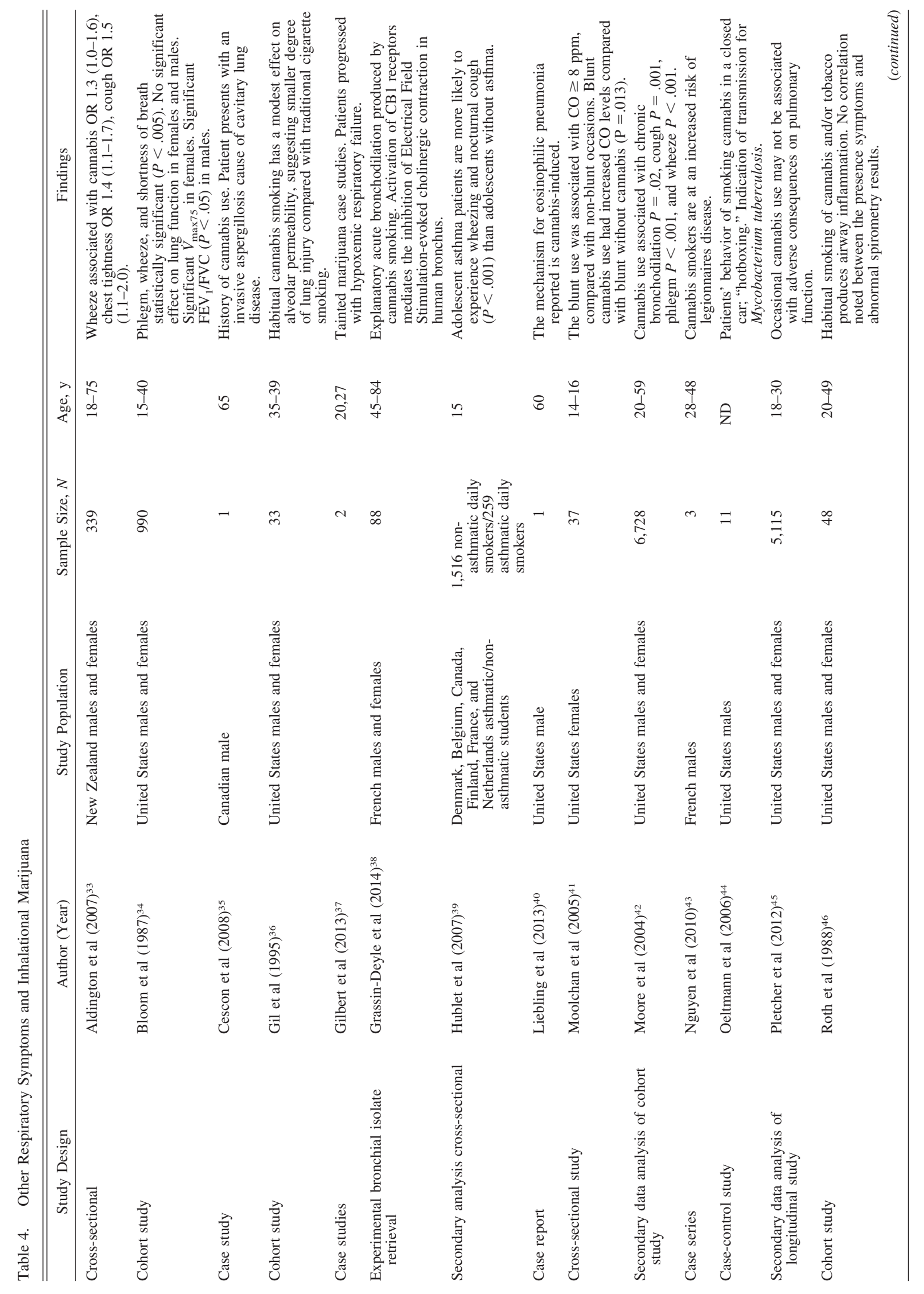




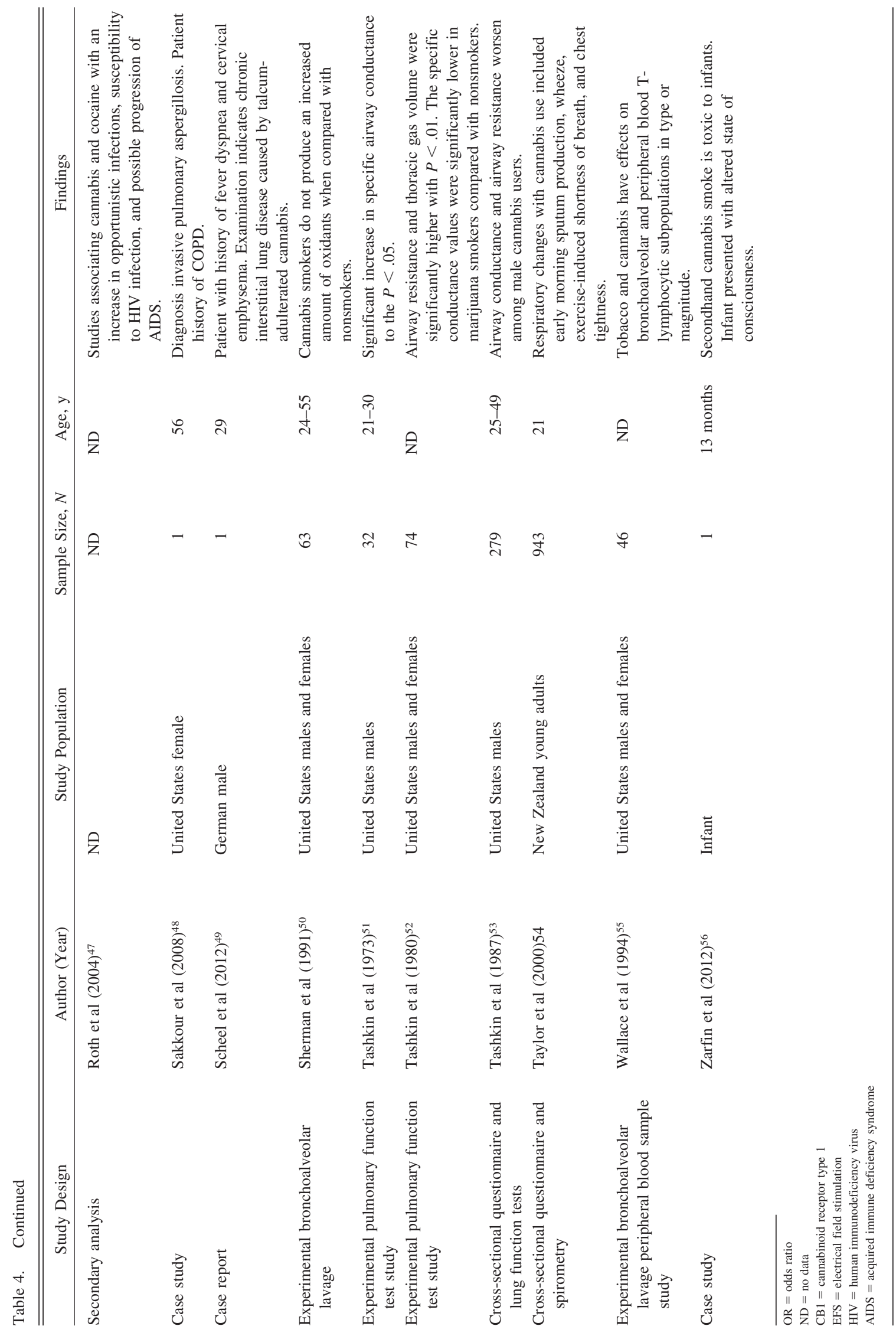


that reflected various respiratory-related symptoms or findings in cannabis smokers.

\section{Results}

Our synthesis of the data represents a more current literature review on the inhalational health effects of marijuana use and other risk factors. ${ }^{57-60}$ Our findings are consistent with other systematic reviews that confirm studies indicating that marijuana use poses negative respiratory effects in smokers. ${ }^{12,16,61}$ Our study categorizes the literature by study type and generalized findings helpful for health-care professionals.

Regarding lung cancer risk, 12 studies were retrieved from the systematic review and are noted in Table 2. Of these studies, 4 were case-control studies, ${ }^{9,11,15,20}$ one was an experimental study, ${ }^{10} 4$ were secondary data analyses of cohort studies, ${ }^{12,13,16,18,21}$ one was a secondary data analysis of pathology reports, ${ }^{19}$ and 2 were case reports. ${ }^{14,17}$ Seven of the studies involved United States participants; one study was based out of New Zealand; one was based out of the United Kingdom; one was a pooled cohort from Tunisia, Morocco, and Algeria; one study involved Swedish military personnel; one study involved a cohort of Australian adults; and a final study was based solely on Tunisian males. The majority of the studies involved male and female adults. Eight of the studies indicated an increased risk of lung cancer from cannabis use or cases indicating lung cancer occurrence, ${ }^{9-12,14,16,17,19,20}$ and 4 studies found either no significant association or a lower risk for lung cancer. ${ }^{13,15,18,21}$ Some of the studies controlled for the effects of tobacco smoking in the data analysis. Of those that found an association, the risk range varied from 2.1- to 4.1-fold increased risk.

Our findings on lung bullae formation indicate research primarily involving case study reports with small sample sizes and 5 studies of larger sample size. Lung bullae were noted in 5 of the cases, as seen in Table 3 . The bullae were noted in the middle to upper lung fields, with one mediastinum case..$^{22,25,27,32,26}$ One subject was diagnosed with a pneumomediastinum upon review of symptoms and $x$-ray. ${ }^{24}$ Use of the bong for cannabis smoking is suggested as probably prompting the pneumomediastinum. Fiorelli et $\mathrm{al}^{22}$ conducted a matched study based on pneumothorax pathology and ascertained that of the study sample, younger smokers age $<35$ y were more likely to exhibit lung bullae.

COPD, emphysema, and lung hyperinflation were also noted in marijuana smokers. ${ }^{23,24,28-31}$ In particular, a study by Tan et $\mathrm{al}^{31}$ assessed self-symptoms and spirometry in a sample of $>800$ Canadian males and females to indicate a relationship between COPD and inhalational marijuana. Hancox et al ${ }^{23}$ published a population-based cohort study and did not find enough evidence for air flow obstruction but did indicate that hyperinflation is related to inhalational marijuana.

Other respiratory symptoms, infectious disease transmission, and altered pulmonary effects were noted in many of the studies found in Table 4. Five studies indicated symptoms such as wheeze, shortness of breath, phlegm production, and/or chest tightness. ${ }^{33,34,39,42,49,54}$ In contrast, 2 studies indicated bronchodilatory effects from inhalational marijuana. ${ }^{38,42}$ From a pulmonary function standpoint, one study found a significant $\dot{\mathrm{V}}_{\max 75}$ in females and a significant $\mathrm{FEV}_{1} / \mathrm{FVC}$ in males. ${ }^{34}$ Studies by Pletcher et $\mathrm{al}^{45}$ and Roth et $\mathrm{al}^{46}$ found no abnormal spirometry. One author found significant increases in specific airway conductance, ${ }^{51}$ whereas a later study found specific airway resistance to be lower in marijuana smokers compared with nonsmokers..$^{52}$ In a later study, the same author found airway conductance and airway resistance to be worsen in male cannabis users. ${ }^{53}$

Aspergillosis, legionnaires, tuberculosis, opportunistic infections, and eosinophilic pneumonia were noted in several studies, probably due to the device harboring opportunistic infectious agents that are inhaled into the respiratory system. ${ }^{35,40,43,44,47,48}$ Several of the bacterial transmission had been found in other shared smoking devices, such as hookah smoking pipes. One study found through bronchoalveolar lavage that the bronchoalveolar effects of cannabis on lymphocytic subpopulations increased in magnitude, ${ }^{55}$ and a contrasting study found smaller degrees of lung injury as compared with traditional cigarette smoking. ${ }^{36}$

Another respiratory effect involved carbon monoxide levels that were assessed with smoking cessation subjects indicating slightly higher $\mathrm{CO}$ levels with blunt use compared with non-cannabis users. ${ }^{41}$ There was no evidence of increased oxidants in cannabis users as compared with nonsmokers. ${ }^{50}$ The secondhand effects of marijuana smoke were evidenced in a case where an infant was exposed to the smoke and experienced altered state of consciousness, indicating that smoking can be toxic around infants. ${ }^{56}$ Tainted marijuana resulted in acute respiratory failure in 2 case reports. ${ }^{37}$

\section{Conclusions}

Although much is known about tobacco smoke, less is known about marijuana smoke, and inferences cannot be made about one based on the other. Both types of smoke contain particulate matter and carcinogens; however, it has been reported that marijuana components may minimize some carcinogenic effects. ${ }^{62}$ The particulate matter has an inflammatory response effect on the pulmonary system. There is some evidence in large studies to indicate that inhalational marijuana has adverse effects on the respiratory system ${ }^{22,25,28,31,34,53}$ and, conversely, bronchodilatory 
effects. ${ }^{42}$ More evidence is needed to support or refute these claims. In particular, direct relationships need to be formulated to avoid confounders in making cause/effect claims. With increasing usage and legalization of marijuana, more research will surface and serve to validate or refute current studies that are presented. Clearly, there are limitations in some of these studies based on self-reporting and also with subjects who smoke cigarettes alongside of their marijuana behavior. It is difficult to make claims of cause and effect with known effects of traditional cigarette smoking confounding some studies. Despite the limited research and limitations in the research on inhalational marijuana, the evidence provided does serve to educate respiratory therapists, pulmonologists, or other health-care professionals and provide knowledge of evidence-based research that can be shared with subjects who currently smoke cannabis.

\section{REFERENCES}

1. National Institute on Drug Abuse, National Institutes of Health. Marijuana Drug Facts. 2015. https://teens.drugabuse.gov/drug-facts/ marijuana. Accessed January 5, 2016.

2. Ashton $\mathrm{CH}$. Pharmacology and effects of cannabis: a brief review. Br J Psychiatry 2001;178:101-106.

3. Hoffmann D, Brunnerman D, Gori G, Wynder E. On the carcinogenicity of marijuana smoke. In: Runeckles VC, editor. Recent Advances in Phytochemistry, Vol. 9, New York: Springer;1975:63-81.

4. Food and Drug Administration. Controlled Substances Act. 2009. http:// www.fda.gov/regulatoryinformation/legislation/ucm148726.htm. Accessed January 5, 2016.

5. Drug Enforcement Administration. https://www.dea.gov/druginfo/ ds.shtml. Accessed January 5, 2016.

6. State Marijuana Laws Map. 2015; http://www.governing.com/ gov-data/state-marijuana-laws-map-medical-recreational.html. Accessed January 5, 2016.

7. National Institute on Drug Abuse, National Institutes of Health. What is the scope of marijuana use in the US? 2015. http://www. drugabuse.gov/publications/research-reports/marijuana/what-scopemarijuana-use-in-united-states. Accessed January 5, 2016.

8. National Institutes of Health. Monitoring the future: 2014 survey results. 2014. http://www.drugabuse.gov/related-topics/trendsstatistics/infographics/monitoring-future-2014-survey-results. Accessed January 5, 2016.

9. Aldington S, Harwood M, Cox B, Weatherall M, Beckert L, Hansell A. et al. Cannabis use and risk of lung cancer: a case-control study. Eur Respir J. 2008;31(2):280-286.

10. Barsky SH, Roth MD, Kleerup EC, Simmons M, Tashkin DP. Histopathologic and molecular alterations in bronchial epithelium in habitual smokers of marijuana, cocaine, and/or tobacco. J Natl Cancer Inst 1998;90(16):1198-1205.

11. Berthiller J, Straif K, Boniol M, Voirin N, Benhaïm-Luzon V, Ayoub, WB, et al. Cannabis smoking and risk of lung cancer in men: a pooled analysis of three studies in Maghreb. J Thorac Oncol 2008; 3(12):1398-1403.

12. Callaghan RC, Allebeck P, Sidorchuk A. Marijuana use and risk of lung cancer: a 40-year cohort study. Cancer Causes Control 2013; 24(10):1811-1820.

13. Chen AL, Chen TJ, Braverman ER, Acuri V, Kemer M, Varshavskiy $\mathrm{M}$, et al. Hypothesizing that marijuana smokers are at a significantly lower risk of carcinogenicity relative to tobacco-non-marijuana smok- ers: evidence based on statistical reevaluation of current literature. J Psychoactive Drugs 2008;40(3):263-272.

14. Graef S, Choo CG, Warfield A, Cullen M, Woolhouse I. Small cell lung cancer in a 26-year-old man with significant Cannabis exposure. J Thorac Oncol 2011:6(1):218-219.

15. Hashibe M, Morgenstern H, Cui Y, Tashkin DP, Zhang ZF, Cozen $\mathrm{W}$, et al. Marijuana use and the risk of lung and upper aerodigestive tract cancers: results of a population-based case-control study. Cancer Epidemiol Biomarkers Prev 2006;15(10):1829-1834.

16. Jemal $\mathrm{A}, \mathrm{Chu} \mathrm{KC}$, Tarone RE. Recent trends in lung cancer mortality in the United States. J Natl Cancer Inst 2001;93(4):277-283.

17. Kothadia JP, Chhabra S, Marcus A, May M, Saraiya B, Jabbour SK. Anterior mediastinal mass in a young marijuana smoker: a rare case of small-cell lung cancer. Case Rep Med 2012;2012:754231.

18. Sidney S, Quesenberry CP Jr, Friedman GD, Tekawa IS. Marijuana use and cancer incidence (California, United States). Cancer Causes Control. 1997;8(5):722-728.

19. Taylor FM 3rd. Marijuana as a potential respiratory tract carcinogen: a retrospective analysis of a community hospital population. South Med J 1988;81(10):1213-1216.

20. Voirin N, Berthiller J, Benhaïm-Luzon V, Boniol M, Straif K, Ayoub WB, et al. Risk of lung cancer and past use of cannabis in Tunisia. J Thorac Oncol 2006;1(6):577-579.

21. Zhang LR, Morgenstern H, Greenland S, Chang SC, Lazarus P, Teare MD, et al. Cannabis smoking and lung cancer risk: pooled analysis in the International Lung Cancer Consortium. Int J Cancer. 2015;136(4):894-903.

22. Fiorelli A, Accardo M, Vicidomini G, Messina G, Laperuta P, Santini M. Does cannabis smoking predispose to lung bulla formation? Asian Cardiovasc Thorac Ann. 2014;22(1):65-71.

23. Hancox RJ, Poulton R, Ely M, Welch D, Taylor DR, McLachlan CR, et al. Effects of cannabis on lung function: a population-based cohort study. Eur Respir J. 2010;35(1):42-47.

24. Hazouard E, Koninck JC, Attucci S, Fauchier-Rolland F, Brunereau L, Diot P. Pneumorachis and pneumomediastinum caused by repeated Muller's maneuvers: complications of marijuana smoking. Ann Emerg Med. 2001;38(6):694-697.

25. Hii SW, Tam JD, Thompson BR, Naughton MT. Bullous lung disease due to marijuana. Respirology 2008;13(1):122-127.

26. Jay AL. Reduced lung function and bullae resulting from illicit drug use. JAAPA 2011;24(7):26-29, 33.

27. Johnson MK, Smith RP, Morrison D, Laszlo G, White RJ. Large lung bullae in marijuana smokers. Thorax 2000;55(4):340-342.

28. Macleod J, Robertson R, Copeland L, McKenzie J, Elton R, Reid P. Cannabis, tobacco smoking, and lung function: a cross-sectional observational study in a general practice population. Br J Gen Pract 2015;65(631):e89-e95.

29. Morris RR. Human pulmonary histopathological changes from marijuana smoking. J Forensic Sci 1985;30(2):345-349.

30. Rooke SE, Norberg MM, Copeland J, Swift W. Health outcomes associated with long-term regular cannabis and tobacco smoking. Addict Behav 2013;38(6):2207-2213.

31. Tan WC, Lo C, Jong A, Xing L, Fitzgerald MJ, Vollmer WM, et al. Marijuana and chronic obstructive lung disease: a population-based study. CMAJ 2009;180(8):814-820.

32. Van Landeghem A, Arys B, Heyse C, Gosselin R. Lung emphysema caused by marijuana smoking. JBR-BTR. 2012;95(3):166-167.

33. Aldington S, Williams M, Nowitz M, Weatherall M, Pritchard A, McNaughton A, et al. Effects of cannabis on pulmonary structure, function and symptoms. Thorax. 2007;62(12):1058-1063.

34. Bloom JW, Kaltenborn WT, Paoletti P, Camilli A, Lebowitz MD. Respiratory effects of non-tobacco cigarettes. BMJ 1987;295(6612): 1516-1518. 


\section{Respiratory EFFects of Inhalational Marijuana}

35. Cescon DW, Page AV, Richardson S, Moore MJ, Boerner S, Gold WL. Invasive pulmonary aspergillosis associated with marijuana use in a man with colorectal cancer. J Clin Oncol 2008;26(13):22142215.

36. Gil E, Chen B, Kleerup E, Webber M, Tashkin DP. Acute and chronic effects of marijuana smoking on pulmonary alveolar permeability. Life Sci 1995;56(23):2193-2199.

37. Gilbert CR, Baram M, Cavarocchi NC. "Smoking wet": respiratory failure related to smoking tainted marijuana cigarettes. Tex Heart Inst J 2013;40(1):64-67.

38. Grassin-Delyle S, Naline E, Buenestado A, Faisy C, Alvarez JC, Salvator $\mathrm{H}$, et al. Cannabinoids inhibit cholinergic contraction in human airways through prejunctional CB1 receptors. Br J Pharmacol 2014;171(11):2767-2777

39. Hublet A, De Bacquer D, Boyce W, Godeau E, Schmid H, Vereecken C, et al. Smoking in young people with asthma. J Public Health 2007;29(4):343-349.

40. Liebling PD, Siu S. A novel cause of eosinophilic pneumonia: recreational marijuana exposure. J Bronchology Interv Pulmonol 2013; 20(2):183-185.

41. Moolchan ET, Zimmerman D, Sehnert SS, Zimmerman D, Huestis MA, Epstein DH. Recent marijuana blunt smoking impacts carbon monoxide as a measure of adolescent tobacco abstinence. Subst Use Misuse 2005;40(2):231-240.

42. Moore BA, Augustson EM, Moser RP, Budney AJ. Respiratory effects of marijuana and tobacco use in a U.S. sample. J Gen Intern Med 2005;20(1):33-37.

43. Nguyen LT, Picard-Bernard V, Perriot J. Legionnaires disease in cannabis smokers. Chest 2010;138(4):989-991.

44. Oeltmann JE, Oren E, Haddad MB, Lake LK, Harrington TA, Ijaz K, et al. Tuberculosis outbreak in marijuana users, Seattle, Washington, 2004. Emerg Infect Dis. 2006;12(7):1156-1159.

45. Pletcher MJ, Vittinghoff E, Kalhan R, Richman J, Safford M, Sidney $\mathrm{S}$, et al. Association between marijuana exposure and pulmonary function over 20 years. JAMA 2012;307(2):173-181.

46. Roth MD, Arora A, Barsky SH, Kleerup EC, Simmons M, Tashkin DP. Airway inflammation in young marijuana and tobacco smokers. Am J Respir Crit Care Med 1998;157(3 Pt 1):928-937.

47. Roth MD, Whittaker K, Salehi K, Tashkin DP, Baldwin GC. Mechanisms for impaired effector function in alveolar macrophages from marijuana and cocaine smokers. J Neuroimmunol 2004; 147(1):82-86

48. Sakkour A, Wang T, Tashkin D. A 56-year-old woman with COPD and multiple pulmonary nodules. Chest 2008;133(2):566-569.
49. Scheel AH, Krause D, Haars H, Schmitz I, Junker K. Talcum induced pneumoconiosis following inhalation of adulterated marijuana, a case report. Diagn Pathol 2012;7:26.

50. Sherman MP, Roth MD, Gong H Jr, Tashkin DP. Marijuana smoking, pulmonary function, and lung macrophage oxidant release. Pharmacol Biochem Behav 1991;40(3):663-669.

51. Tashkin DP, Shapiro BJ, Frank IM. Acute pulmonary physiologic effects of smoked marijuana and oral 9-tetrahydrocannabinol in healthy young men. N Engl J Med 1973;289(7):336-341.

52. Tashkin DP, Calvarese BM, Simmons MS, Shapiro BJ. Respiratory status of seventy-four habitual marijuana smokers. Chest 1980;78(5): 699-706.

53. Tashkin DP, Coulson AH, Clark VA, Simmons M, Bourque LB, Duann $\mathrm{S}$, et al. Respiratory symptoms and lung function in habitual heavy smokers of marijuana alone, smokers of marijuana and tobacco, smokers of tobacco alone, and nonsmokers. Am Rev Respir Dis 1987;135(1):209-216.

54. Taylor DR, Poulton R, Moffitt TE, Ramankutty P, Sears MR. The respiratory effects of cannabis dependence in young adults. Addiction 2000;95(11):1669-1677.

55. Wallace JM, Oishi JS, Barbers RG, Simmons MS, Tashkin DP. Lymphocytic subpopulation profiles in bronchoalveolar lavage fluid and peripheral blood from tobacco and marijuana smokers. Chest 1994;105(3):847-852.

56. Zarfin Y, Yefet E, Abozaid S, Nasser W, Mor T, Finkelstein Y. Infant with altered consciousness after cannabis passive inhalation. Child Abuse Negl 2012;36(2):81-83.

57. Howden ML, Naughton MT. Pulmonary effects of marijuana inhalation. Expert review of respiratory medicine. 2011;5(1):87-92.

58. Mehra R, Moore BA, Crothers K, Tetrault J, Fiellin DA. The association between marijuana smoking and lung cancer: a systematic review. Arch Intern Med. 2006;166(13):1359-1367.

59. Tetrault JM, Crothers K, Moore BA, Mehra R, Concato J, Fiellin DA. Effects of marijuana smoking on pulmonary function and respiratory complications: a systematic review. Arch Intern Med 2007; 167(3):221-228.

60. Wang T, Collet JP, Shapiro S, Ware MA. Adverse effects of medical cannabinoids: a systematic review. CMAJ 2008;178(13): 1669-1678

61. Lee PN, Forey BA. Why are lung cancer rate trends so different in the United States and United Kingdom? Inhal Toxicol 2003;15(9): 909-949.

62. Melamede R. Cannabis and tobacco smoke are not equally carcinogenic. Harm Reduct J 2005;2:21. 